\title{
Identifying the Factors for Ensuring Customers Actively Engaged in Smart Grids
}

\author{
Linda Hull ${ }^{1}$, Even Bjørnstad ${ }^{2}$, Yvonne Boerakker ${ }^{3}$, Magnus Brolin ${ }^{4}$, Yeoungjin Chae ${ }^{5}$ and Duncan Yellen ${ }^{6}$ \\ 1. Strategic Asset Management, EA Technology Ltd., Chester CH1 6ES, UK \\ 2. Enova SF, Oil and Energy, Trondheim N-7030, Norway \\ 3. Policy Advisory and Research, DNV GL, Arnhem 6800, Netherlands \\ 4. Energy Technology Department, SP Technical Research Institute of Sweden, Göteborg 400 22, Sweden \\ 5. Planning Division, KPX, Bitgaramro 625, Korea \\ 6. Smart Grid Delivery, EA Technology Ltd., Chester CH1 6ES, UK
}

Received: July 30, 2014 / Accepted: October 10, 2014 / Published: January 31, 2015.

\begin{abstract}
Smart grids are expected to become an essential component of the future energy system. The technical potential of smart grids is far reaching and increasingly well understood, and smart grids are now in the early phases of market deployment in several regions, particularly, in Europe and the US. Less understood than the technical aspects is how and to what degree end users (i.e. the customers) are willing and able to embrace smart grid technologies and the changes in mindset associated with this transition. This article reports the main findings from an IEA (International Energy Agency)-DSM (demand side management) project addressing the role of customers in a smart grid deployment scheme, specifically how customer behavior may restrict the technical potential of smart grids from being realized. With a model of household energy behavior as the theoretical point of departure, the research builds on experiences from various smart grid pilot studies, together with consumer research within similar domains, to identify behavioral challenges that are likely to hamper adoption of "smart grid behaviors". Based on this insight, a set of recommendations to minimize customer resistance to smart grid deployment is suggested.
\end{abstract}

Key words: Smart grid, energy behavior, consumer, barriers.

\section{Introduction}

Security of supply and sustainability are two strategic issues related to the future energy system. The concept of "smart grid" represents an important part of the solution to these issues, particularly in relation to the functioning of the electricity grid. This article reports the key findings from an international project carried out within the DSM (demand side management) implementing agreement of the IEA (International Energy Agency), explores how end users of electric energy interact with smart grid related initiatives, how behavioral barriers may limit the efficiency of smart

Corresponding author: Linda Hull, senior consultant, research fields: demand side management and energy networks. E-mail: Linda.Hull@eatechnology.com. grid, and how these barriers could be addressed.

The key hypotheses of the project is that the behavior of end users is a key factor of the success of smart grid initiatives, and that the factor is not well understood by implementers of smart grid initiatives. Further, smart grid research has had a main focus on system technologies and has, to a much lesser degree, addressed the human dimension - the customer behavior of the smart grid. With this article, we propose a platform for analyzing the customer issues, and aim at revealing the most important "traps" to be avoided by smart grid implementers. We combine both theoretical knowledge and empirical work in this process, the findings of which may function as useful guidelines for smart grid implementers and policy makers.

The article is structured in the following way: the 
authors start with a brief overview of the main issues characterizing the smart grid and energy behavior research (Section 2). Next, in Section 3, the authors outline the theoretical platform upon which their empirical interpretations rest. Section 4 states the typical goals of smart grid initiatives, while Section 5 discusses the typical pitfalls related to these, by giving examples of challenging behavioral issues and how they could be handled. Conclusions are presented in Section 6.

\section{Smart Grids: A Brief Review}

One of the major future global challenges concerns the need for a sustainable and reliable energy supply. This is being addressed in several strategic documents and roadmaps on an international level, such as the IEA Energy Technology Perspectives 2014 [1] and the Europe 2020 Strategy [2]. Concerning electrical power, it is foreseen that renewable power sources, such as wind and solar, will increase significantly and will play an important role in the future power system. It is also projected that the importance of electricity will increase in the future, on the one hand, due to a large-scale introduction of electric vehicles, increased use of heat pumps, etc., and on the other hand, due to the need to achieve carbon emission reduction targets. This development implies a new diversity in the power system, and a transformation of the system from being centralized towards a more decentralized one [3]. This constitutes a paradigm shift, resulting in new challenges requiring new solutions to ensure the reliability and energy security of the system. This leads to the idea of a smart grid, addressing and providing the solutions to these issues. End users will play a key role in delivering effective smart grids.

Due to this central role of consumers (grid customers), research has been carried out concerning the system and market impact of measures on the demand side. Examples of such research are presented in Refs. [4-8]. Also simulations on a detailed level have been made to assess the technical potential of flexibility in households [9-12]. All of these are based on a theoretical technological and/or statistical approach to describe the consumption of electricity. A related topic is the control of residential electrical loads, including heating and cooling, electric vehicles, appliances etc.. Technical solutions aiming at optimizing residential load patterns are presented in Refs. [13-15]. The future role of electric vehicles, such as smart charging and applied as local storage, has been addressed in Refs. [16-18]. In these papers, the technological functions and performance of control devices are described and analyzed. However, still lacking in the above described analyses is a discussion on how to motivate and entice consumers to adopt and/or to use the described technology. This is a complex issue, not in the least due to its inter-disciplinary nature, involving several research areas, such as technology, economics, psychology and sociology.

The main aim of this paper is to give insight into this issue, namely, the factors ensuring the engagement of consumers in smart grids. For this purpose, the focus in terms of the "consumer" is on households and small business end users of electric energy and their "energy behavior" (see definition in Section 3). Understanding the energy behavior of the target group is fundamental for all implementation of energy related policies, programs and technologies. The theoretical underpinning of this concept has evolved, but we may take the neoclassical economics theory as a point of departure. The traditional economics position is that energy behavior is largely understood as an outcome of an investment type decision, where the expected present value of the investment is the key decision parameter. Empirical evidence has challenged this position by demonstrating that consumers often make decisions that are not "rational" from a purely economic perspective. This so called "energy paradox" was debated during the 1990s, and a range of explanations was suggested to account for these seemingly irrational behaviors [19-22].

In addressing the purely economic perspective of 
smart grids, financial incentives can be used to motivate the demand side. Examples of pricing schemes, tariffs and the impact on consumption can be found in Refs. [5, 23, 24]. However, financial incentives are often not sufficient, and may not be effective for all consumer segments. Economic incentives may be enhanced by visualization of electricity consumption, environmental impact, etc. to induce changes in energy consumption patterns. Research has been performed to analyze the impact of different visualization techniques on consumers, and examples are presented in Refs. [25, 26].

In addition, a large number of demonstrations and pilots worldwide have been carried out. Many of these have addressed the issue of flexibility in residential areas, where different technologies and offers have been deployed. A few examples are the SDG \& E (San Diego Gas and Electric) Reduce Your Use Day (US) [27], PG \& E (Pacific Gas and Electric) Smart Rate (US) [28], Jeju Island Test Bed (KR) [29], Customer Led Network Revolution (UK) [30], and the introduction of time-of-use tariffs in Italy (IT) [31]. There are also a few reports giving an international overview of various demonstrations and pilots, including Refs. [32, 33]. An overall conclusion from the review of these studies is that there is a need to look beyond the purely economic and technical mechanisms to understand the engagement of consumers in smart grids.

In parallel with, and partly as a consequence of these research findings, theoretical models of energy behavior have evolved that challenge the neoclassical model. Space prohibits a comprehensive discussion of these; however, some interesting characteristics may be mentioned. A social psychological approach, such as the Theory of Planned Behavior, focuses more on fundamental personal traits, such as norms, attitudes and beliefs, in explaining decisions and behaviors [34]. This and similar approaches widen the basis of explanatory variables from the narrower focus on economic variables. A much used approach to explain technology diffusion, suggested by Rogers [35], is also useful to explain how certain energy behaviors spread in society. This theory rests on an assumption of "psychological heterogeneity" among consumers, whereby the change-oriented risk taking innovators and early adopters implement certain energy behaviors (technologies) at a much earlier stage than the mainstream consumers. An important practical application of this theory is for change agents to exploit the dynamics of the differences between these consumer segments.

Economic and psychological models typically focus on the individual decision maker in understanding energy behavior. There are theoretical positions that question this approach on ontological grounds, and claim that the energy behavior of an individual is not to be understood as discrete "energy decisions", but rather is the result of different everyday practices, trivial habits at home and in the workplace. "Practice theory" exemplifies this position, where focus is more on the general context of living, the practice of everyday life with the routines and technologies involved, and the energy use implied by this [36].

It might be that the wide mix of energy behaviors, ranging from daily routine behaviors to single "once in a lifetime" investment decisions, is not explained by a single theory. It is our view, however, that an implementer of smart grid technologies should have some theoretical reference points for guidance in order to understand the target group (customer base) better, and thereby be better able to justify and tailor the implementation to customer needs, address the relevant barriers, and thus, achieve a more optimal smart grid implementation process. From this overview of smart grid issues, we therefore turn in the next section to a more specific discussion of theories of energy behavior.

\section{Energy Behaviors and Practices}

As demonstrated in the literature review above, there is a wide ranging and complex set of factors that influence the way that consumers interact with smart 
grid related activities, i.e., their energy behaviors. In general terms, an energy behavior refers to any action or decision taken by the consumer (decision maker) that affects the energy use of the consumer. More specifically, any given "energy behavior" should be defined in terms of a few key elements. Firstly, it involves a decision maker; the individual or other entity that makes the decision and performs the behavior. The second element is a well-defined outcome or action. This could be switching off lights, buying low energy light bulbs, reducing indoor temperature or deciding when to use a washing machine. Further, the context is relevant, i.e., does the action take place at home, at work or in the car? Finally, the time is also an important element, both in terms of defining the point in time of the initial decision and the duration/frequency of the action if it is repeated: Is it a one-off action that takes place today, or is it repeated over several weeks and months?

Once the behavior is well defined, a theoretical model of behavior can be used to help understand the factors that influence the decision maker's choice over whether to perform the behavior or not.

\subsection{Energy Behavior Model}

A number of models or frameworks of understanding exist. No single model or framework of understanding is considered to be ideal, but they are a useful tool to help understand and achieve an outcome that depends on behavior change.

Some models focus on individuals actors; others focus on the individual in his/her social environment. Some focus only on the behavior per se; other models are more concerned with the wider social, material and economic context within which the behavior is performed. Some theoretical positions focus on one-off behaviors; others on habitual day-to-day activities. Some focus on discrete actions; others consider a complex set of inter-related actions.

It is believed that valuable insights can be gained from considering both the characteristics of the individual, and also the physical, social and political context within which the decision is made. We therefore chose to base our work on the following model of energy behavior (Fig. 1), which represents a synthesis of several theoretical positions [34, 37]:

This model gives several messages. Firstly, it indicates, by the "core" represented by the shaded boxes, that the characteristics of the decision maker represent an important determinant of behavioral decisions;

Secondly, there is a distinction between discrete one-off decisions, which are often the concrete outcome of a deliberate (planned) decision process, and

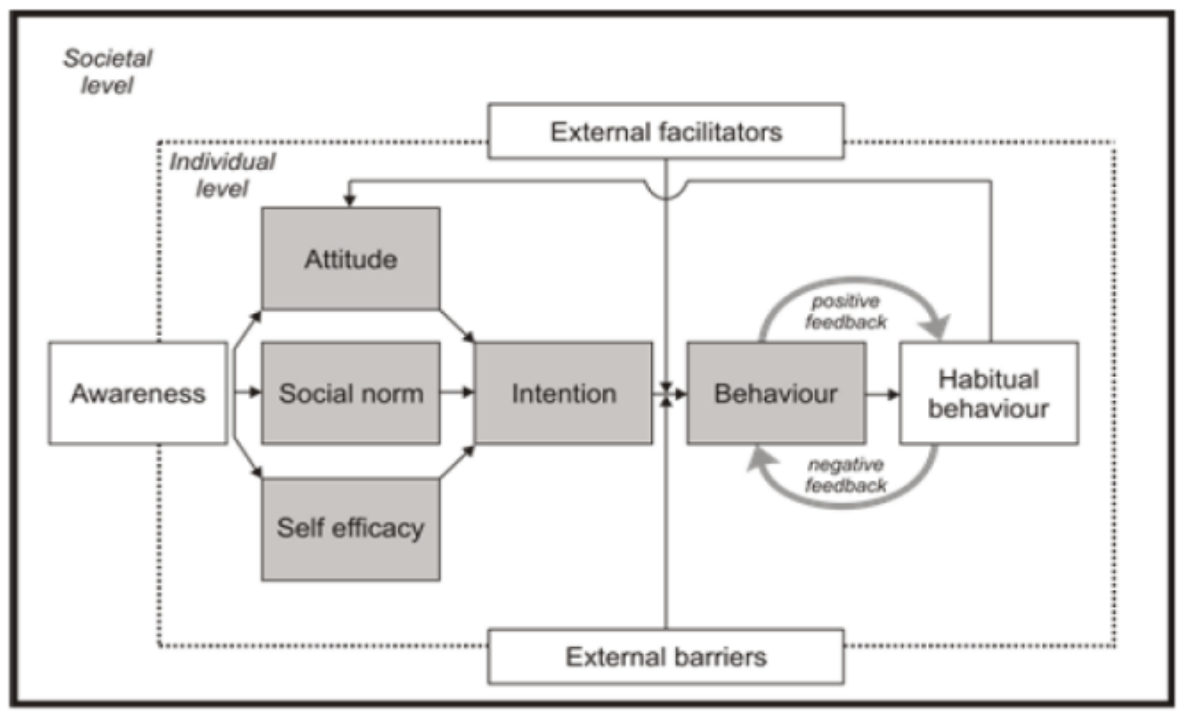

Fig. 1 Theoretical model of energy behavior. 
habitual behaviors, which become routine over time once established and where the actual "decision" may be more blurred. The process of establishing a "pristine" behavior may thus be different from the process of changing an established habit.

Thirdly, there are factors outside the control of the decision maker, such as external barriers and facilitators, and the general societal context that also need to be understood when analyzing an energy behavior. Regulations, market conditions, prices, climate, infrastructure, etc. are examples of such variables. In empirical analyses across countries/regions, it is important to be aware that differences in the societal context may become an important variable that explains different "rationalities" at the individual level. Our model of energy behavior thus accounts for central elements of both the individualistic and the more system-oriented models discussed in the literature review.

\subsection{Diffusion of Behaviors}

As mentioned above, the core of the energy behavior model is the individual, and the "psychological characteristics" of the individual decision maker represents important explanatory variables of behavior. There is much evidence that different decision makers make different decisions in a given situation. Rogers [35] suggests that different psychological characteristics of the consumers, decision makers, explain these differences. Applied to new technologies, this manifests itself in the typical observation that the diffusion over time of a new technology is often described by an S-curve. An interpretation of this process is that "innovators" and "early adopters" first adopt the new technology, later to be followed by the "mainstream" and, possibly, the "laggards". This process is explained by different psychological profiles of the different customer segments (see Fig. 2).

We suggest that this theory is relevant also for the introduction of smart grid technology. Some consumer groups are curious, open and proactive towards the new technology, and are eager to use it. Others are skeptical, even suspicious to new technologies, including smart grid technology. These may even refuse to have the technology installed in their home.

A particular problem should be mentioned in this respect. Diffusion processes are often illustrated by a smooth and continuous curve, indicating that the process proceeds by its own force once it has gained some momentum. However, as pointed out by Moore [38], this diffusion process may very well stop after the innovators and early market consumers have adopted the technology. This means that there might be a "chasm" separating these early market segments and the mainstream market, as illustrated in Fig. 2. A smart grid deployment process should therefore pay specific attention to the problem of crossing the chasm.

\section{Outcomes Required}

A range of smart grid related initiatives have been trialed and, in some cases, rolled out to large numbers of consumers. Those involving an element of consumer energy behavior change have focused on delivering one or more of the following outcomes:

(1) An overall reduction in energy consumption. This may seem the logical place to start, but if the primary goal is to reduce peak demands, it may be more effective to focus on changing the pattern of consumption.

(2) A different, but enduring, underlying pattern of consumption. This can be used to address situations where peak demands occur over extended periods of time (i.e., over several months of the year).

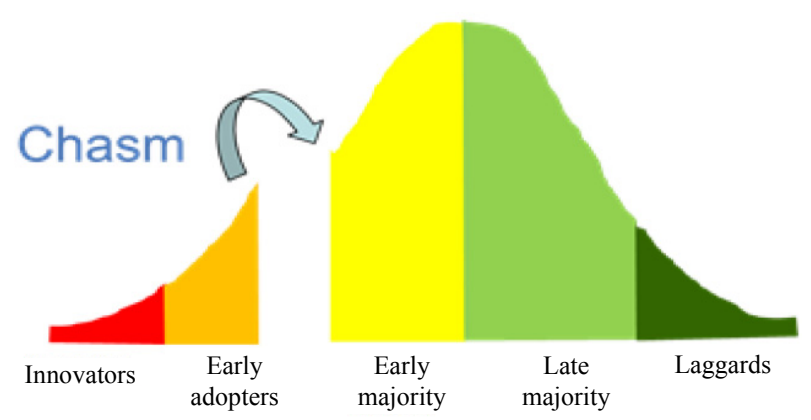

Fig. 2 Diffusion of innovations model. 
(3) A pattern of consumption that responds dynamically to the varying operational requirements faced by the electricity system. Achieving this outcome is beneficial for dealing with short term constraints that require changes to the pattern of demand on an infrequent and unpredictable basis.

(4) Enabling industry stakeholders to access and utilize energy consumption information. Improved information about electricity usage and voltage levels on the distribution networks offers the potential to improve the efficiency of the electricity system. Smart meter data can help network operators optimize the way they manage and operate their networks and can reduce the need for network investment.

Which of these outcomes are required will depend on the specific context of the smart grid initiative, and this context is likely to vary between countries and regions. This context may also be influential on the behavioral responses of the initiative, as pointed out by our theoretical model.

\section{Designing Customer Offerings}

There are a number of different factors that need to be taken into consideration when designing a smart grid initiative to ensure that consumers are willing to engage. This implies that consumers "sign up" to the initiative, undertake any actions that enable them to participate (i.e., install technologies) and deliver the required outcomes.

\subsection{Provide Choice}

When an individual is unhappy with a situation (s), he can react by exiting (choosing something else) or voicing their concerns (protesting). Therefore, it is important to provide consumers with an element of choice. These protests can, in some cases, be extreme. For example, one woman in Houston, Texas, brandished a gun at a utility worker to prevent the installation of a smart meter in her home.

However, it is also important to ensure that consumers are not faced with too many choices; otherwise, they can be paralyzed by an inability to choose from the myriad of options available to them [39]. This is attributed to a number of factors including concerns that they may make the wrong choice (the anticipation of regret) and the difficulty of assessing the trade-offs between the different options.

Therefore, it is important to provide consumers with choices, but not too many.

\subsection{Provide Tangible Benefits}

A significant amount of analysis has been undertaken, and is currently on-going, to demonstrate the benefits of smart grids. Many of these studies focus on the benefits to industry stakeholders or on the benefits to society as a whole. However, it is important to ensure that they also provide tangible benefits directly to consumers themselves.

A review of a number of surveys of consumer attitudes and views towards smart grid related activities shows that consumers generally say that they prefer/expect to receive a financial reward [40].

Tangible benefits are not just limited to direct financial benefits, but include other aspects, such as improved comfort, improved health or reduced environmental impact.

\subsection{Take Care When Framing the Initiative}

The way that smart grid initiatives are framed has an important impact on the way they are assessed and evaluated by consumers.

As indicated in the energy behavior model in Fig. 1, an individual's decision to perform an action depends on a number of factors, including their own views, opinions and beliefs. This implies that different segments of consumers react (behave) in different ways in response to a given initiative. So it is not possible to make generalizations that apply to all individuals. However, some general observations can be made about how the framing options can have an important impact on the decision making process.

This includes focusing on the avoidance of losses 
rather than achieving benefits, taking care over the reference point used to compare benefits and the timing of payments and benefits. An example of "avoidance of losses" is provided below.

Many consumers are risk averse, i.e., they are reluctant to take a course of action that has an uncertain outcome. They are more likely to select an option with a certain outcome, even if the expected outcome from an alternative, but uncertain, option is higher. However, individuals are much more willing to "take a gamble" where losses are involved.

The following is a well cited example of the powerful effect of framing on decision making that was originally developed by Tversky and Kahneman [41].

Consider a scenario where an unusual disease is expected to kill 600 people. Two alternative programs have been proposed to combat the disease, with different outcomes expected. The way that these programs are framed has a significant impact on which of the proposed programs is preferred.

If the options are framed in terms of how many people are saved (option 1: 200 people saved, option 2: $1 / 3$ probability that 600 people will be saved, but $2 / 3$ probability that no-one will be saved), the majority (72\%) select option 1.

If, however, the options are framed in terms of how many people will die (option 3: 400 people will die, option $4: 1 / 3$ probability that no-one will die but $2 / 3$ probability that everyone will die), the majority (78\%) select option 4.

Therefore, there may be advantages in framing the initiative in terms of avoiding waste or losses rather than in terms of the benefits that could be achieved.

\subsection{Ensure Consumer Concerns Are Addressed}

Consumer concerns must be identified and addressed. The results of previous field trials and case studies provide a useful starting point for identifying concerns, but it is important to realize that the results of one study will not necessarily apply to a different group of consumers or within a different context.
For example, smart meters have been rolled out to all of Enel's consumers in Italy. The roll out was driven by Enel's desire to improve the cost effectiveness of their metering activities, and consumers were not provided with any choice over whether or not they wished to have a smart meter. Despite the lack of choice, no strong opposition was raised by consumers.

The same is not true for consumers in the Netherlands, for example. A mandatory roll-out was proposed, with consumers facing a possible $€ 17,000$ fine or six months imprisonment for refusal. Consumers and consumer groups raised concerns over the violation of right to privacy and the possibility that the data could be misused. This led to the Dutch First Chamber refusing to approve the Smart Metering Bill.

A review of a number of smart grid related case studies and surveys of consumer opinions conducted as part of the project shows that there is a wide range of issues that present barriers to consumer engagement.

Consumer concerns relating to health, safety and data privacy are reasonably well documented, but it is important that other concerns are not overlooked.

\subsubsection{Disruption and Inconvenience}

Consumers cited a number of concerns relating to disruption to their property or routines. In particular, the impact on time is important.

Many relate to the installation process itself, i.e., the inconvenience associated with the time spent waiting for installers to arrive and during the installation process itself. In addition, householders cite that they can be put off by the installation process itself, i.e., due to the need to move possessions in order to allow the installation to take place or the need to redecorate after the installation has been completed.

Although seemingly innocuous, these concerns can have a significant impact on consumer engagement. For example, large numbers of consumers are put off having free or subsidized loft insulation fitted within their home due to upheaval and disruption. This is particularly true when large volumes of possessions are stored in the loft which would need to be relocated. 
Consumers also cite a general dislike of people coming into their home, for example, to install new technologies. This relates to not only the inconvenience caused, but also concern over the potential for damage. For example, an Australian demand response trial involved installing technology to allow the air-conditioning equipment of householders to be controlled remotely. The trail reported that householders were more likely to participate if their air-conditioning units were located outdoors [42].

5.4.2 Financial Commitments and Uncertainty over Benefits

The anticipation of regret, i.e., of being worse off, is an important factor influencing consumer willingness to participate. The possibility that they will end up paying more than they do at the moment that outweighs the possibility that they will end up paying less.

Some schemes remove the risk by providing assurances that consumers will not pay more under the new initiative than they would have done on their existing tariff. Whilst, this may help consumers enroll, it may not necessarily provide a cost effective approach for stakeholders. For example, the principle of not exposing the consumers to any risks can constitute a barrier to a larger rollout by a distribution operator. It may lower revenue and thereby decrease the possibilities for the network operator to invest and operate the system.

It is essential to provide consumers with information that is as accurate and reliable as possible, rather than "best case" scenarios. Claims that smart meters can help householders save up to $10 \%$ on their bills typically represent the upper limit on the savings obtained from trials. In practice, many consumers achieve savings much lower than this, leading to dissatisfaction and disappointment.

Lack of confidence over the level of benefits could be even more important where an individual has to make an upfront investment in order to participate, i.e., they know how much they need to invest but may not have certainty over when (or if) they will get a return on their investment.

However, it is important to note that ensuring a financial incentive in return for participation is not sufficient to ensure that consumers will take action. This does not imply they are behaving irrationally, but rather that there are other factors that are considered to be more important.

\section{Conclusions}

Over the coming years, smart grids offer the potential to support the move to a low carbon future. They could help to deliver a fundamental change in the way that the balance of electricity supply and demand is managed. In particular, they enable a coordinated approach whereby the actions of all users connected to the energy system can be integrated. This includes the actions of the consumers themselves.

However, there is a real risk that if consumers do not adopt new approaches to the way that they consume electricity, smart grids may not be able to achieve their full potential.

A neo-classical economic analysis of the potential benefits and losses does not accurately predict whether a consumer will adopt a particular initiative or technology. Rather, there are a number of different factors and elements that influence the decision maker; only some of which have been identified in this paper.

Understanding these factors, addressing consumer concerns and ensuring that smart grids provide tangible benefits to consumers are important aspects to be taken into consideration when designing smart grid initiatives.

A number of general guidelines can be identified in order to help ensure a smart grid initiative that is more likely to be adopted by consumers: a selection of which have been identified here. However, the decision of whether or not to engage is always made by an individual.

The factors that influence the decision making process are wide-ranging and complex. As a result, an initiative that is successful for one group of consumers 
may not necessarily be effective with another group in a similar context due to the differing views and beliefs of the individuals involved. Likewise, what works for one group of consumers may not succeed with another group of like-minded consumers due to the existence of differing opportunities and barriers.

\section{Acknowledgments}

The authors wish to thank the following for supporting this research: Enova SF, Norway; EA Technology, UK; DNV GL, Netherlands; SP Technical Research Institute of Sweden, Sweden; KPX, Korea and all of the members of the stakeholder teams that supported the project.

\section{References}

[1] International Energy Agency. 2014. Energy Technology Perspectives 2014-Harnessing Electricity's Potential. Paris: IEA Publications.

[2] European Commission. 2010. Communication from the Commission: EUROPE 2020-A Strategy for Smart, Sustainable and Inclusive Growth. A report by COM, Brussels.

[3] International Energy Agency. 2011. Technology Roadmap: Smart Grids. Paris: IEA Publications.

[4] Moghaddam, M. P., Abdollahi, A., and Rashidinejad, M. 2011. "Flexible Demand Response Programs Modeling in Competitive Electricity Markets." Applied Energy 88 (9): 3257-699.

[5] Albadi, M. H., and El-Saadany, E. F. 2008. "A Summary of Demand Response in Electricity Markets." Electric Power Systems Research 78 (11): 1989-96.

[6] Ma, O., Alkadi, N., Cappers, P., Denholm, P., Dudley, J., Goli, S., Hummon, M., Kiliccote, S., MacDonald, J., Matson, N., Olsen, D., Rose, C., Sohn, M. D., Starke, M., Kirby, B., and O'Malley, M. 2013. "Demand Response for Ancillary Services." IEEE Transactions on Smart Grid 4 (4): 1988-95.

[7] Olsen, D. J., Matson, N., Sohn, M., Rose, C., Dudley, J., Goli, S., and Kilicote, S. 2013. Grid Integration of Aggregated Demand Response, Part 1: Load Availability Profiles and Constraints for the Western Interconnection. Technical report.

[8] Hummon, M., Palchak, D., Denholm, P., Jorgenson, J., Olsen, D. J., Matson, N., and Kiliccote, S. 2013. Grid Integration of Aggregated Demand Response, Part 2: Modeling Demand Response in a Production Cost Model. Technical report.
[9] Widén, J., and Wäckelgård, E. 2010. “A High-Resolution Stochastic Model of Domestic Activity Patterns and Electricity Demand." Applied Energy 87 (6): 1880-92.

[10] Richardson, I., Thomson, M., Infield, D., and Clifford, C. 2010. "Domestic Electricity Use: A High-Resolution Energy Demand Model." Energy and Buildings 42 (10): 1878-87.

[11] Capasso, A., Grattieri, W., Lamedica, R., and Prudenzi, A. 1994. "A Bottom-up Approach to Residential Load Modeling." IEEE Transactions on Power Systems 9 (2): 957-64.

[12] Gottwalt, S., Ketter, W., Block, C., Collins, J., and Weinhardt, C. 2011. "Demand Side Management-A Simulation of Household Behavior under Variable Prices." Energy Policy 39 (12): 8163-74.

[13] Pedrasa, M. A. A., Spooner, T. D., and MacGill, I. F. 2010. "Coordinated Scheduling of Residential Distributed Energy Resources to Optimize Smart Home Energy Services." IEEE Transactions on Smart Grid 1 (2): 134-43.

[14] Mohsenian-Rad, A. H., and Leon-Garcia, A. 2010. "Optimal Residential Load Control with Price Prediction in Real-Time Electricity Pricing Environments." IEEE Transactions on Smart Grid 1 (2): 120-33.

[15] Fernandesa, F., Moraisa, H., Valea, Z., and Ramosa, C. 2014. "Dynamic Load Management in a Smart Home to Participate in Demand Response Events." Energy and Buildings 82 (Oct.): 592-606.

[16] Papadaskalopoulos, D., Strbac, G., Mancarella, P., Aunedi, M., and Stanojevic, V. 2013. "Decentralized Participation of Flexible Demand in Electricity Markets-Part II: Application with Electric Vehicles and Heat Pump Systems." IEEE Transactions on Power Systems 28 (4): 3667-74.

[17] Peterson, S. B., Whitacre, J., and Apt, J. 2010. “The Economics of Using Plug-in Hybrid Electric Vehicle Battery Packs for Grid Storage." Journal of Power Sources 195 (8): 2377-84.

[18] Sortomme, E., and El-Sharkawi, M. A. 2011. "Optimal Charging Strategies for Unidirectional Vehicle-to-Grid." IEEE Transactions on Smart Grid 2 (1): 131-8.

[19] Hassett, K. A., and Metcalf, G. E. 1993. "Energy Conservation Investment: Do Consumers Discount the Future Correctly?.” Energy Policy 21 (6): 710-6.

[20] Jaffe, A. B., and Stavins, R. N. 1994. "The Energy Paradox and the Diffusion of Conservation Technology." Resource and Energy Economics 16 (2): 91-122.

[21] Metcalf, G. E. 1994. "Economics and Rational Conservation Policy." Energy Policy 22 (10): 819-25.

[22] GGolove, W. H., and Eto, J. H. 1996. Market Barriers to Energy Efficiency: A Critical Reappraisal of the Rationale for Public Policies to Promote Energy Efficiency. A report 
by Lawrence Berkeley National Laboratory.

[23] Bartusch, C., Wallin, F., Odlare, M., Vassileva, I., and Wester, L. 2011. "Introducing a Demand-Based Electricity Distribution Tariff in the Residential Sector: Demand Response and Customer Perception." Energy Policy 39 (29): 5008-25.

[24] Herter, K. 2007. "Residential Implementation of Critical-Peak Pricing of Electricity.” Energy Policy 35 (4): 2121-30.

[25] Ellegård, K., and Palm, J. 2011. "Visualizing Energy Consumption Activities as a Tool for Making Everyday Life More Sustainable.” Applied Energy 88 (5): 1920-6.

[26] Bonino, D., Corno, F., and Russis, L. D. 2012. "Home Energy Consumption Feedback: A User Survey." Energy and Buildings 47 (April): 383-93.

[27] SDG \& E. 2014. "Reduce Your Use Day." http://www.sdge.com/save-money/reduce-your-use/reduc e-your-use-rewards.

[28] PG \& E. 2014. Accessed September 29, 2014. http://www.pge.com/.

[29] Korea Smart Grid Institute 2012, "Jeju Island Test Bed." Accessed July 11, 2013. http://www.smartgrid.or.kr.

[30] Northern PowerGrid 2013, "Customer Led Network Revolution (CLNR)” Accessed April 24, 2013, http://www.networkrevolution.co.uk.

[31] Maggiore, S., Gallanti, M., Grattieri, W., and Benini, M. 2013. "Impact of the Enforcement of a Time-of-Use Tariff to Residential Customers in Italy." In Proceedings of CIRED the 22nd International Conference on Electricity Distribution, 1-4.

[32] Uyterlinde, M. 2014. "Report on Case Analyses, Success Factors and Best Practices.” Accessed October 28, 2014. http://www.s3c-project.eu/.
[33] Mulder, W., Kumpavat, K., Faasen, C., Verheij, F., and Vaessen, P. 2012. Global Inventory and Analysis of Smart Grid Demonstration Projects. DNV KEMA report.

[34] Fishbein, M., and Ajzen, I. 2010. Predicting and Changing Behavior: The Reasoned Action Approach. New York: Psychology Press.

[35] Rogers, E. M. 2003. Diffusion of Innovations. New York: Free Press.

[36] Nicolini, D. 2012. Practice Theory, Work, and Organization: An Introduction. Oxford, UK: Oxford University Press.

[37] Egmond, C., and Bruel, R. 2007. Nothing Is as Practical as a Good Theory: Analysis of Theories and a Tool for Developing Interventions to Influence Energy-Related Behavior. A report by SenterNovem.

[38] Moore, G. A. 2002. Crossing the Chasm: Marketing and Selling Disruptive Products to Mainstream Customers. New York: HarperCollins.

[39] Abbott, B., Mannella, A., Mcnamara, K., and Tripathy, A. 2007. "Optimising Choices for How People Really Buy, Not How We Think They Buy, Diamond Management and Energy Consultants." Accessed September 29, 2014. http://www.slideshare.net/easiegmann/predictably-irratio nal-customers.

[40] Hull, L. 2013. Interaction between Consumers and Smart Grid Related Initiatives. IEA DSM task 23 report.

[41] Tversky, A., and Kahneman, D. 1986. "The Framing of Decisions and the Evaluation of Prospects." Studies in Logic and the Foundations of Mathematics 114: 503-20.

[42] Essential Services Commission of South Australia. 2007. Demand Management Program Interim Report No.1. June 2007. 